\title{
ORIGINAL ARTICLE Multivariate heredity of melanin-based coloration, body mass and immunity
}

\author{
S-Y Kim ${ }^{1}$, JA Fargallo ${ }^{2}$ P Vergara ${ }^{2,3}$ and J Martínez-Padilla ${ }^{2}$ \\ The genetic covariation among different traits may cause the appearance of correlated response to selection on multivariate \\ phenotypes. Genes responsible for the expression of melanin-based color traits are also involved in other important physiological \\ functions such as immunity and metabolism by pleiotropy, suggesting the possibility of multivariate evolution. However, little is \\ known about the relationship between melanin coloration and these functions at the additive genetic level in wild vertebrates. \\ From a multivariate perspective, we simultaneously explored inheritance and selection of melanin coloration, body mass and \\ phytohemagglutinin (PHA)-mediated immune response by using long-term data over an 18-year period collected in a wild \\ population of the common kestrel Falco tinnunculus. Pedigree-based quantitative genetic analyses showed negative genetic \\ covariance between melanin-based coloration and body mass in male adults and positive genetic covariance between body mass \\ and PHA-mediated immune response in fledglings as predicted by pleiotropic effects of melanocortin receptor activity. Multiple \\ selection analyses showed an increased fitness in male adults with intermediate phenotypic values for melanin color and \\ body mass. In male fledglings, there was evidence for a disruptive selection on rump gray color, but a stabilizing selection on \\ PHA-mediated immune response. Our results provide an insight into the evolution of multivariate traits genetically related with \\ melanin-based coloration. The differences in multivariate inheritance and selection between male and female kestrels might \\ have resulted in sexual dimorphism in size and color. When pleiotropic effects are present, coloration can evolve through a \\ complex pathway involving correlated response to selection on multivariate traits. \\ Heredity (2013) 111, 139-146; doi:10.1038/hdy.2013.29; published online 17 April 2013
}

Keywords: animal coloration; animal model; genetic correlation; pleiotropy; quantitative genetics; selection

\section{INTRODUCTION}

The evolutionary dynamics of morphological and physiological phenotypes is often complex to understand, particularly when the underlying molecular mechanisms are genetically associated by pleiotropy. An important remaining question in evolutionary biology lays on explaining how evolutionary conflicts resulted from selection acting on genetically correlated phenotypes are resolved (McGuigan et al., 2011). Current advances in this field paved the way for empiricists to study the evolution of correlated traits by measuring complex phenotypes and determining their genetic basis. Indeed, the use of pedigree-based quantitative genetic analyses has played an important role in improving our understanding about the relationship between different fitness-related traits (reviewed in Kruuk et al., 2008). Nevertheless, the question of how the multiple traits of morphology and physiology evolve simultaneously remains scarcely explored in wild vertebrates because of the lack of long-term monitoring on genetically correlated phenotypes and measurements of natural selection acting on the complex phenotypes (McGuigan et al., 2011).

Melanin is the most widespread pigment in animal coloration across diverse taxa, and its expression has been attributed to a variety of adaptive strategies and functions in mate choice, social conflicts, predation avoidance and protection (reviewed in Hill and McGraw, 2006a). Interestingly, melanin-based coloration is often correlated with other physiological, morphological and behavioral traits at the phenotypic level. A recent study proposed that this association is based on pleiotropic effects of the pigmentation genes, regulating the synthesis of melanin-based colorations (Ducrest et al., 2008). Inter-individual phenotypic variation in melanin pigmentation is widespread in most animals, including model systems in which a number of genes involved in melanin pigmentation have been identified (Hoekstra, 2006; Hubbard et al., 2010). The most important candidate gene for the pleiotropic effects up to date is the proopiomelanocortin (POMC), a highly conserved gene across all vertebrates with few exceptions (Ducrest et al., 2008). The melanocortins produced by the POMC gene bind to the melanocortin-1 receptor (MC1R), which has a fundamental importance in melanin synthesis (Hoekstra, 2006; Mundy, 2006), as well as four other melanocortin receptors (MC2-5R). Importantly, these melanocortin receptors (MCRs) are also involved in functions other than melanin pigmentation, such as immune inflammation, metabolism, food intake, energy expenditure, exocrine gland activity, aggressiveness, sexual behavior and hypothalamic-pituitary-adrenal stress response (Ducrest et al., 2008). Melanocortins binding to MC3-4R reduce food intake and stimulate energy expenditure, thereby promoting reduction of adipose mass tissue and preventing overweight (Ducrest et al., 2008). By binding to MC1R, MC3R and MC5R, melanocortins also reduce acute and allergic inflammation (Ducrest et al., 2008). However,

${ }^{1}$ Departamento de Ecoloxía e Bioloxía Animal, Universidade de Vigo, Vigo, Spain; ²Departamento de Ecología Evolutiva, Museo Nacional de Ciencias Naturales-CSIC, José Gutiérrez Abascal 2, Madrid, Spain and ${ }^{3}$ School of Biological Sciences, University of Aberdeen, Aberdeen, UK 
covariance among these functions at the additive genetic level remains unexplored in both laboratory and wild vertebrates.

Here, we use an extensive data set over an 18-year period from a wild population of the common kestrel (Falco tinnunculus Linnaeus) to study quantitative genetics of melanin-based color traits (see Supplementary Figure 1) and other genetically related traits. Previous studies suggest that the expression of melaninbased coloration in kestrels is associated with indicators of body condition, mate choice and environmental conditions (Fargallo et al., 2007a,b; Vergara and Fargallo, 2008; Vergara et al., 2009; Parejo et al., 2011).

Our aim in this study was to improve our understanding of the evolution of multivariate phenotypes by examining the genetic architecture and selection of melanin coloration, body mass and phytohemagglutinin (PHA)-mediated immune response. Body mass depends on the levels of food intake and energy expenditure, which is influenced by metabolic rate, physical activity and energy homeostasis. The cell-mediated immune response measured as the local inflammatory response to the PHA mitogen reflects the capacity of inflammatory response (Martin et al., 2006; Ardia and Schat, 2008) and immune activity by several types of immune cells (Tella et al., 2008). First, to estimate additive genetic and environmental (co) variations in univariate and multivariate phenotypes, we used a pedigree-based quantitative genetic analysis, 'animal model'. Second, we tested natural selection on the single and multivariate traits by using standard methods to estimate selection differentials and gradients. We expect to find evidence for a positive genetic correlation between melanin coloration and PHA-mediated immune response and a genetic trade-off between melanogenesis and body mass, if there is a strong pleiotropic effect mediated by the POMC gene over these traits (Ducrest et al., 2008).

\section{MATERIALS AND METHODS}

\section{Study species and field procedures}

The common kestrel is a small raptor sexually dimorphic in size and plumage and shows a relatively short lifespan, with the majority of individuals breeding only up to age of $3-4$ years ( $91 \%$ of breeders in the study population are 1-4 years old). In the study population, kestrels lay a clutch of three to seven eggs (mean \pm s.d. $=5.0 \pm 0.8, N=577$ pairs) and fledge up to seven chicks successfully (mean $=3.7 \pm 1.8, N=558$ pairs). The common kestrel exhibits great inter-sexual and individual variations in melanin-based plumage coloration. Gray, black and brown feathers are melanin-based colorations (Fargallo et al., 2007a) and reddish-brown back feathers do not contain carotenoids (Casagrande et al., 2006).

The study was carried out in a common kestrel population in the Campo Azálvaro region, Spain, where most kestrels breed in nest boxes. Reproduction (laying date, clutch size, hatching and fledging success) was recorded for all nests every year between 1995 and 2012. Most female breeders were captured twice during incubation and chick-rearing periods and males were captured only during chick-rearing to measure tail length, body mass and color traits. Most adults were captured in the morning between 0700 and 1200 hours. Body mass was measured in 1836 chicks of age 25-26 days (close to fledging) from 1995 to 2012. Body mass of nestlings was not affected by sampling time of day (Martínez-Padilla, 2006). Rump color was measured in 1420 fledglings from the 1998-2012 cohorts and PHA-mediated immune response in 1105 fledglings from the 2000-2009 cohorts. Immune response was measured using the common assay of intradermal injection of a mitogen (PHA) and measurement of subsequent skin inflammation as a surrogate of T-cell-mediated immunocompetence (for details, see Fargallo et al., 2002). All chicks were sexed by means of a discriminant function before 2000 and by molecular methods (Fridolfsson and Ellegren, 1999) using a blood sample since 2000. All fledglings and breeders were individually marked with steel rings for identification.

\section{Color trait measurements}

Rump color in female adults was measured since 1998 (except 1999), and rump color in fledglings of both sexes was measured since 2001 by direct observation in the field (Supplementary Figure 1). The percentage of gray with respect to brown, covering the whole rump, was estimated $(0 \%=$ completely black-barred brown and 100\%=completely black-barred gray; Supplementary Figure 1). These measurements were highly repeatable and were closely correlated with measurements taken from digital pictures (for details, see Fargallo et al., 2007a; for repeatabilities and correlations, see Vergara et al., 2009: $r>0.90$ ). Rump of adult males is completely (100\%) gray.

Both males and females have a wide black subterminal band in tails (Fargallo et al., 2007a; Vergara et al., 2009). In most captured adults since 1997, the width of black subterminal tail band in six tail feathers on the left side were measured with digital calliper. These measurements are highly repeatable (see Vergara et al., 2009 for repeatability: $r=0.98$ ). Tail band width was positively correlated to tail length at the phenotypic level (but not at the additive genetic level). Therefore, we used the percentage of black tail band width in the whole tail length for further analyses.

\section{Pedigree information and quantitative genetic analyses}

The animal model, a kind of mixed effect model, estimates quantitative genetic parameters of traits by assessing the phenotypic covariance between all pairs of relatives in the pedigree (Kruuk, 2004). In our study, univariate and multivariate animal models with a restricted maximum likelihood were fitted to the pedigree of adult and young kestrels to estimate (co)variance components and total phenotypic (co)variances for different traits, using ASReml v3 (Gilmour et al., 2008).

The estimation of the additive genetic (co)variances was based on pedigree information of 2716 individuals, including 308 maternal and 398 paternal identities. Siblings from the same brood in which paternal and/or maternal identity is unknown were assigned a common 'dummy' parental identity (60 maternal and 220 paternal identities) to preserve sibship information (see also Coltman, 2005; Husby et al., 2010). The rate of extra-pair paternity has been found to be low (below 5\% of offspring) in another common kestrel population (Korpimäki et al., 1996). Previous studies showed that extra-pair paternity rates of less than $20 \%$ have a negligible impact on quantitative genetic estimates given sufficient sample sizes (Merilä et al., 1998; Charmantier and Reale, 2005). Pedigree statistics was performed using the $\mathrm{R}$ package PEDANTICS (Morrissey and Wilson, 2010). Mean maternal and paternal sibship sizes in the pedigree were 6.41 and 4.96 , respectively. Full details of the pedigree statistics and the graphical representation are shown in Supplementary Table 1 and Supplementary Figure 2.

All adults that bred between 1995 and 2012 and all fledglings from the 1995-2012 cohorts, except the experimental chicks from the 2004 cohort (Fargallo et al., 2007b), were used for quantitative genetic analyses. Fledglings and adults of each sex were analyzed in separate models because adult- and fledgling-specific traits were measured and the two sexes show dimorphism in size and color.

In the univariate animal model fitted to each trait of adults, a trait of an individual $i$ is specified as:

trait $_{i}=\mu+$ age class $i+a_{i}+p e_{i}+y_{i}+e_{i}$.

In the model, the population mean $(\mu)$ was included as a fixed effect. Oneyear-old breeders show intermediate coloration between young and adults (Village, 1990). Therefore, age class (age 1 year/older) was also included as a fixed effect in the analyses. As random effects, we included the additive genetic $\left(a_{i}\right)$, individual-specific (permanent environment, $p e_{i}$ ) and year-specific (common environment, $y_{i}$ ) effects and the residual term $\left(e_{i}\right)$. Besides the genetic effect, $p e_{\mathrm{i}}$ accounts for environmental effects on individual's phenotype due to constant differences in conditions experienced by different individuals throughout their lives or to long-term effects of conditions experienced during early development (Kruuk, 2004); $y_{i}$ quantifies the covariance among individuals sharing common environments (for example, food type and abundance, population density and weather). We also fitted multivariate animal models to test for genetic, environmental and phenotypic correlations between different adult traits, which showed a significant additive genetic variance in univariate animal models (that is, black tail band and body mass; 
see Results). Additive genetic, permanent environment and year were included as random effects in the bivariate animal models.

The univariate animal model fitted to a trait of fledglings is specified as:

trait $_{i}=\mu+$ laying date $e_{i}+a_{i}+n_{i}+y_{i}+e_{i}$.

In this model, laying date was included as a fixed effect. Nest site, that is, identity of nest box at a permanent location $\left(n_{i}\right)$ and year of birth $\left(y_{i}\right)$ were included as additional random effects to quantify the covariances among individuals sharing particular common environments. Brood identity was not included as a variance component because its effect is confounded with nest site effect and genetic effect as all nestlings were raised together with their genetic siblings in their nests of origin. Multivariate animal models for fledgling traits (that is, rump gray color, body mass and PHA-mediated immune response) were also fitted. Additive genetic, year (cohort) and nest site effects were included as random effects in the trivariate animal models of fledglings.

The distribution of all random effects, additive genetic $\left(a_{i}\right)$, permanent environment $\left(p e_{i}\right)$, common environment $\left(n_{i}\right.$ and $\left.y_{i}\right)$ and the residual term $\left(e_{i}\right)$ is assumed to have a mean of zero and a variance to be estimated $\left(V_{\mathrm{A}}, V_{\mathrm{PE}}, V_{\mathrm{N}}\right.$, $V_{\mathrm{Y}}$ and $V_{\mathrm{R}}$ ). For the univariate animal models fitted to adults and chicks, total phenotypic variance $\left(V_{\mathrm{P}}\right)$ was calculated as:

$$
V_{\mathrm{P}}=V_{\mathrm{A}}+V_{\mathrm{PE}}+V_{\mathrm{Y}}+V_{\mathrm{R}} \text {, and } V_{\mathrm{P}}=V_{\mathrm{A}}+V_{\mathrm{N}}+V_{\mathrm{Y}}+V_{\mathrm{R}} \text {. }
$$

Heritability, permanent environment effect and common environment effects (nest and year effects) were calculated as:

$$
h^{2}=V_{\mathrm{A}} / V_{\mathrm{P}}, p e^{2}=V_{\mathrm{PE}} / V_{\mathrm{P}}, n^{2}=V_{\mathrm{N}} / V_{\mathrm{P}} \text { and } y^{2}=V_{\mathrm{Y}} / V_{\mathrm{P}} \text {. }
$$

In order to enable comparison with other traits and populations, we also provide the coefficient of additive genetic variance $\mathrm{CV}_{\mathrm{A}}$ (Houle, 1992) in which the additive genetic variance is scaled by the trait mean $(\bar{X})$ :

$$
\mathrm{CV}_{\mathrm{A}}=100 \times \sqrt{V_{\mathrm{A}}} / \bar{X} \text {. }
$$

Phenotypic and genetic correlations $\left(r_{\mathrm{P}}\right.$ and $\left.r_{\mathrm{A}}\right)$ among the traits were calculated based on additive genetic (co)variances $\left(V_{\mathrm{A}}\right.$ and $\left.\operatorname{Cov}_{\mathrm{A}}\right)$ and phenotypic (co)variances $\left(V_{\mathrm{P}}\right.$ and $\left.\operatorname{Cov}_{\mathrm{P}}\right)$ estimated from the multivariate animal models. Note that near-zero variances were fixed at zero to allow model convergence and avoid wrong estimation of other (co)variances due to the non-estimable parameters in the multivariate animal models (Gilmour et al., 2008).

The statistical significance of each (co)variance component was assessed using a likelihood ratio test that compares two models, the unconstrained model and the model with (co)variance component reduced. Particularly, the multivariate animal model was reduced by fixing a covariance at zero to perform a likelihood ratio test comparison with the full model. The likelihood ratio test is based on -2 times the difference in restricted maximum likelihood $\log$-likelihood scores distributed as $\chi^{2}$, where the degrees of freedom equalled the difference between the two models tested.

\section{Natural selection analyses}

To estimate selection on quantitative traits of adults that bred in 1995-2011, we used annual fitness that calculates an individual's genetic contribution to the population based on the sum of the survival of its fully related self and fledgling of the offspring sharing its genes. Hence, an annual fitness of individual $i$ at time $t$ was calculated (Brommer et al., 2007; see also Coulson et al., 2006; Foerster et al., 2007) as:

$$
w_{t(i)}=s_{t(i)}+\frac{1}{2} f_{t(i)} .
$$

For individual $i$ in year $t, s_{t(i)}$ is a binary variable of survival from year $t$ to $t+1$, and $f_{t(i)}$ is the number of fledglings produced in year $t$. To estimate selection on traits of fledglings from the 2001-2008 cohorts, we used binary probability of recruitment, which reflects post-fledging survival, as a fitness estimate (eg, Roulin et al., 2010).

We used standard methods to estimate selection gradients and differentials on the study traits (Lande and Arnold, 1983; Arnold and Wade, 1984a, b). All traits were standardized (zero mean, unit variance) within the subset of data on which an analysis was performed. Annual fitness, $w_{t(i)}$, of adults and recruitment probability of fledglings were converted to relative fitness (standardized mean of 1). Selections on adult traits were estimated using linear mixed effect models with individual identity as a random effect to account for repeated measures on the same individuals (Husby et al., 2011). Generalized linear models with a binomial error distribution and a logit link were used to estimate selections of fledglings. Standardized directional and stabilizing selection differentials $\left(S^{\prime}\right.$ and $\left.c^{\prime}\right)$ were estimated by fitting linear and squared variables in the models. Then we assumed indirect selection for multiple traits and estimated standardized directional and nonlinear selection gradients $\left(\beta^{\prime}\right.$ and $\left.\gamma^{\prime}\right)$ by using multiple linear mixed effect models and generalized linear models. The coefficients for the squared terms were doubled to calculate nonlinear selection differentials and gradients (Stinchcombe et al., 2008), which are often interpreted as stabilizing (when negative) or the total strength of disruptive (when positive) selection. We also estimated the standardized correlational selection gradient $\left(\gamma_{i j}^{\prime}\right)$, which measures the selection acting on the covariance between different traits, by fitting the interaction.

We quantified the expected response $R$ to selection by using the following multivariate breeder's equation, appropriate for variance-standardized selection gradient (Roff 1997; Coltman et al., 2005) for trait $i$ as:

$$
R_{i}=\beta_{i} h_{i}^{2}+\sum_{i \neq j} \beta_{j} h_{i} h_{j} r_{\mathrm{A}(i j)} .
$$

\section{RESULTS}

\section{Quantitative genetics of adult traits}

Univariate animal model of females provided evidence of significant additive genetic, common environment (year) variances for black tail band, that is, \% width in tail length $\left(h^{2} \pm\right.$ s.e. $=0.670 \pm 0.046, p e^{2}=0$, $y^{2}=0.076 \pm 0.039$; Table 1 ). Rump gray colors (\% gray coloration) of females did not show significant additive genetic effects $\left(h^{2}=0.205 \pm 0.196\right.$; Table 1$)$. Body mass during chick rearing showed significant additive genetic and year effects but nonsignificant permanent environment effect $\left(h^{2}=0.533 \pm 0.162, p e^{2}=0.010 \pm\right.$ $\left.0.154, y^{2}=0.087 \pm 0.040\right)$.

In males, both black tail band and body mass had significant

\begin{tabular}{|c|c|c|c|c|c|c|c|}
\hline Trait & $\mathrm{N}$ & Trait mean \pm s.e. & $\mathrm{V}_{A} \pm$ s.e. & $V_{P E} \pm$ s.e. & $V_{Y} \pm$ s.e. & $\mathrm{V}_{P} \pm$ s.e. & $\mathrm{CV}_{A}$ \\
\hline \multicolumn{8}{|l|}{ Females ( $\mathrm{N}=293$ individuals) } \\
\hline Black tail band width $(\%)^{\mathrm{a}}$ & 433 & $11.665 \pm 0.083$ & $1.476 \pm 0.177(P<0.001)$ & $<10^{-6}(P=0.964)$ & $0.167 \pm 0.091(P=0.002)$ & $2.203 \pm 0.189$ & 10.41 \\
\hline Rump gray color $(\%)^{\mathrm{a}}$ & 384 & $59.219 \pm 1.465$ & $134.84 \pm 130.40(P=0.258)$ & $221.06 \pm 131.32(P=0.059)$ & $53.84 \pm 30.29(P<0.001)$ & $656.33 \pm 59.086$ & 19.61 \\
\hline Body mass ( $\mathrm{g}$, chick rearing $)^{\mathrm{a}}$ & 450 & $246.12 \pm 0.894$ & $171.77 \pm 56.55(P=0.003)$ & $3.15 \pm 49.66(P=0.888)$ & $28.01 \pm 13.88(P<0.001)$ & $322.42 \pm 26.30$ & 5.33 \\
\hline \multicolumn{8}{|l|}{ Males $(\mathrm{N}=188$ individuals) } \\
\hline Black tail band width (\%) & 255 & $15.163 \pm 0.152$ & $2.177 \pm 0.283(P<0.001)$ & $<10^{-6}(P=1)$ & $0.003 \pm 0.021(P=0.906)$ & $2.626 \pm 0.277$ & 9.73 \\
\hline Body mass ( $\mathrm{g}$, chick rearing) ${ }^{\mathrm{b}}$ & 263 & $179.190 \pm 0.845$ & $113.52 \pm 18.73(P=0.026)$ & $<10^{-5}(P=1)$ & $37.20 \pm 20.35(P<0.001)$ & $202.81 \pm 25.63$ & 5.95 \\
\hline
\end{tabular}
additive genetic components, showing high levels of heritability (black tail band: $h^{2}=0.829 \pm 0.032, p e^{2}=0, y^{2}=0.001 \pm 0.008$; body mass: $h^{2}=0.560 \pm 0.079, p e^{2}=0, y^{2}=0.183 \pm 0.085$; Table 1).

Table 1 Quantitative genetics on color traits and body mass in common kestrel adults from univariate animal models

Note: model, trait ${ }_{i}=\mu+$ age class $i+a_{i}+p e_{i}+y_{i}+e_{i}$.

aFixed effect, age class: $P$-values $<0.001$

${ }^{b}$ Fixed effect, age class: $P$-values $<0.001$ 
Black tail band and body mass of females were positively correlated at the genetic, environmental and phenotypic levels, but the positive covariance was significant only at the phenotypic level (Table 2). However, the two traits of males were significantly negatively correlated at the genetic and phenotypic levels (Table 2).

\section{Quantitative genetics of fledgling traits}

Univariate animal model of female fledglings showed that the total phenotypic variance of gray color in rump (\%) was explained by a significant proportion of additive genetic variance $\left(h^{2}=0.088 \pm\right.$ $0.080, y^{2}=0.003 \pm 0.010, n^{2}=0.017 \pm 0.023$; Table 3$)$. Here, the additive genetic effect, although significant, showed a high level of standard error possibly due to the relatively little phenotypic variance compared with that of males. Additive genetic effects for body mass and PHA-mediated immune response were also high and significant in female fledglings (body mass: $h^{2}=0.799 \pm 0.072$, $y^{2}=0.037 \pm 0.022, n^{2}=0.069 \pm 0.030 ;$ PHA response: $h^{2}=0.465 \pm$ $0.099, y^{2}=0.225 \pm 0.090, n^{2}=0.056 \pm 0.031$; Table 3).

Univariate animal models of male fledglings also provided evidence of significant additive genetic variances in all three traits (rump gray color: $h^{2}=0.835 \pm 0.084, y^{2}=0.087 \pm 0.042, n^{2}=0$; body mass: $h^{2}=0.888 \pm 0.068, \quad y^{2}=0.037 \pm 0.022, \quad n^{2}=0.051 \pm 0.025 ; \quad$ PHA response: $h^{2}=0.547 \pm 0.100, \quad y^{2}=0.185 \pm 0.079, \quad n^{2}=0.074 \pm 0.036$; Table 3).

Multivariate analyses of the three fledgling traits showed similar patterns of multitrait relationships in male and female fledglings. Most remarkably, body mass and PHA-mediated response were significantly positively correlated both at the genetic and phenotypic levels in both sexes (Table 4). Gray coloration in rump and body mass of females were significantly negatively correlated at the phenotypic level, but not at the genetic level (Table 4). Negative phenotypic covariance between gray color and PHA-mediated immune response in males was also significant (Table 4).

\section{Selection}

Both simple and multiple linear selection analyses with annual fitness, $w_{t(i)}$, showed significant positive directional selection on body mass in female adults $\left(S_{i}^{\prime}=0.086, \beta^{\prime}{ }_{i}=0.074\right)$ (Table 5; Figure 1a), suggesting that heavy females are favored in terms of survival and reproduction. There was no selection on black tail band of female adults (Table 5). There was no evidence for either directional or stabilizing selection on body mass in male adults. However, simple and multiple analyses provided evidence for stabilizing selection (negative selection differential and gradient) on black tail band in males $\left(c_{i}^{\prime}=-0.076\right.$, $\gamma_{i}^{\prime}=-0.078$; Table 5). Furthermore, there was a significant negative correlational selection on black tail band and body mass for male adults $\left(\gamma_{i j}^{\prime}=-0.057\right.$; Table 5), showing increased fitness in males with intermediate phenotypic values for both traits (Figure $1 \mathrm{~b}$ ).

In fledglings, all selection analyses with recruitment probability as a fitness estimate showed nonsignificant selection on female traits (Table 6). Both simple and multiple selection analyses showed a significant disruptive selection on rump gray color of male fledglings (positive selection differential and gradient; $c_{i}{ }_{i}=0.297, \gamma_{i}^{\prime}=0.328$; Table 6). On the other hand, nonlinear selection differential and gradient on PHA-mediated immune response of male fledglings were significant and negative $\left(c_{i}^{\prime}=-0.433, \gamma_{i}^{\prime}=-0.445\right.$; Table 6$)$, suggesting a stabilizing selection on this trait. Multiple regression analysis provided evidence for a significant negative correlational selection between rump gray color and PHA-mediated immune response in male fledglings $\left(\gamma_{i j}^{\prime}=-0.471\right.$; Table 6; Figure 2). In general, intermediate levels of PHA-mediated immune response were selected, but males with weak immune response and strong gray coloration showed the highest recruitment probability.

\section{DISCUSSION}

Our quantitative genetic analysis revealed that melanin-based color traits in a wild population of common kestrels possess high and significant additive genetic variation similar to other birds

Table 2 Additive genetic, permanent environment (individual), year and phenotypic covariances and genetic and phenotypic correlations between a color trait (black tail band) and body mass during chick rearing in common kestrel adults from bivariate animal models for females and males

\begin{tabular}{|c|c|c|c|c|c|c|}
\hline & $\operatorname{Cov}_{A} \pm$ s.e. & $\operatorname{Cov}_{P E} \pm$ s.e. & $\operatorname{Cov}_{Y} \pm$ s.e. & $\operatorname{Cov}_{P} \pm$ s.e. & Genetic correlation & Phenotypic correlation \\
\hline Females & $2.905 \pm 1.532(P=0.054)$ & n.e. ${ }^{a}$ & $1.065 \pm 0.886(P=0.265)$ & $3.265 \pm 1.690(P=0.021)$ & $0.178 \pm 0.094$ & $0.122 \pm 0.061$ \\
\hline Males & $-3.226 \pm 1.645(P=0.042)$ & n.e. ${ }^{a}$ & n.e. ${ }^{a}$ & $-3.247 \pm 1.582(P=0.034)$ & $-0.204 \pm 0.100$ & $-0.141 \pm 0.067$ \\
\hline
\end{tabular}

an.e.: non-estimable due to an extremely small or zero variance.

Table 3 Quantitative genetics on melanin-based rump gray coloration, body mass and PHA-mediated immune response in common kestrel fledglings from univariate animal models

\begin{tabular}{|c|c|c|c|c|c|c|c|}
\hline Trait & $\mathrm{N}$ & Trait mean \pm s.e. & $\mathrm{V}_{A} \pm$ s.e. & $\mathrm{V}_{Y} \pm$ s.e. & $\mathrm{V}_{N} \pm$ s.e. & $V_{P} \pm$ s.e. & $C V_{A}$ \\
\hline \multicolumn{8}{|l|}{ Females } \\
\hline Rump gray color $(\%)^{a}$ & 704 & $2.340 \pm 0.343$ & $7.327 \pm 6.703(P<0.001)$ & $0.240 \pm 0.860(P=0.777)$ & $1.402 \pm 1.952(P=0.480)$ & $83.515 \pm 4.526$ & 115.68 \\
\hline Body mass $(g)^{b}$ & 923 & $221.98 \pm 0.75$ & $376.06 \pm 46.618(P<0.001)$ & $17.25 \pm 10.50(P=0.003)$ & $32.40 \pm 14.88(P=0.004)$ & $470.70 \pm 29.422$ & 8.74 \\
\hline PHA response $(\mathrm{mm})^{\mathrm{a}}$ & 556 & $4.230 \pm 0.051$ & $0.697 \pm 0.148(P<0.001)$ & $0.337 \pm 0.171(P<0.001)$ & $0.835 \pm 0.473(P=0.014)$ & $1.499 \pm 0.192$ & 19.74 \\
\hline \multicolumn{8}{|l|}{ Males } \\
\hline Rump gray color (\%) & 716 & $23.78 \pm 0.86$ & $454.65 \pm 61.56(P<0.001)$ & $47.26 \pm 24.55(P<0.001)$ & $<10^{-4}(P=1)$ & $544.58 \pm 40.25$ & 89.67 \\
\hline Body mass $(\mathrm{g})^{\mathrm{b}}$ & 913 & $198.56 \pm 0.65$ & $327.28 \pm 37.58(P<0.001)$ & $13.44 \pm 8.14(P=0.003)$ & $18.71 \pm 9.40(P=0.006)$ & $368.63 \pm 22.95$ & 9.11 \\
\hline PHA response $(\mathrm{mm})^{\mathrm{a}}$ & 549 & $3.732 \pm 0.047$ & $0.707 \pm 0.137(P<0.001)$ & $0.239 \pm 0.124(P<0.001)$ & $0.950 \pm 0.471(P=0.007)$ & $1.292 \pm 0.147$ & 22.53 \\
\hline
\end{tabular}

Abbreviation: PHA, phytohemagglutinin.

Note: model, trait ${ }_{i}=\mu+$ laying date ${ }_{i}+a_{i}+n_{i}+y_{i}+e_{i}$.

aFixed effect, laying date: $P$-values $\geq 0.242$.

bFixed effect, laying date: $P$-values $<0.001$. 
Table 4 Additive genetic, year (cohort), nest site and phenotypic covariances and genetic and phenotypic correlations between melanin-based gray rump coloration (\%), body mass $(\mathrm{g})$ and PHA-mediated immune response $(\mathrm{mm})$ in common kestrel fledglings from multivariate (three traits) animal models

\begin{tabular}{|c|c|c|c|c|c|c|}
\hline Covariances & $\operatorname{Cov}_{A} \pm$ s.e. & $\operatorname{Cov}_{Y} \pm$ s.e. & $\operatorname{Cov}_{N} \pm$ s.e. & $\operatorname{Cov}_{p} \pm$ s.e. & $\begin{array}{c}\text { Genetic } \\
\text { correlation }\end{array}$ & $\begin{array}{l}\text { Phenotypic } \\
\text { correlation }\end{array}$ \\
\hline \multicolumn{7}{|l|}{ Females } \\
\hline $\begin{array}{l}\text { Rump gray-body } \\
\text { mass }\end{array}$ & $19.609 \pm 14.031(P=0.209)$ & n.e. & $3.303 \pm 3.902(P=0.439)$ & $-2.95 \pm 8.21(P=0.014)$ & $0.373 \pm 0.297$ & $-0.015 \pm 0.041$ \\
\hline $\begin{array}{l}\text { Rump gray-PHA } \\
\text { response }\end{array}$ & $0.156 \pm 0.729(P=0.841)$ & n.e. & $0.046 \pm 0.209(P=0.841)$ & $-0.381 \pm 0.462(P=0.177)$ & $0.069 \pm 0.324$ & $-0.034 \pm 0.041$ \\
\hline $\begin{array}{l}\text { Body mass-PHA } \\
\text { response }\end{array}$ & $6.000 \pm 2.072(P=0.003)$ & $-0.415 \pm 1.186(P=0.806)$ & $0.339 \pm 0.607(P=0.597)$ & $5.707 \pm 1.719(P<0.001)$ & $0.370 \pm 0.113$ & $0.215 \pm 0.065$ \\
\hline \multicolumn{7}{|l|}{ Males } \\
\hline $\begin{array}{l}\text { Rump gray—body } \\
\text { mass }\end{array}$ & $31.753 \pm 35.196(P=0.383)$ & $15.119 \pm 11.477(P=0.149)$ & n.e. & $30.427 \pm 22.337(P=0.086)$ & $0.083 \pm 0.093$ & $0.068 \pm 0.049$ \\
\hline $\begin{array}{l}\text { Rump gray-PHA } \\
\text { response }\end{array}$ & $-1.192 \pm 2.206(P=0.313)$ & $-2.574 \pm 1.667(P=0.120)$ & n.e. & $-4.236 \pm 2.051(P=0.017)$ & $-0.067 \pm 0.124$ & $-0.155 \pm 0.068$ \\
\hline $\begin{array}{l}\text { Body mass-PHA } \\
\text { response }\end{array}$ & $6.567 \pm 1.722(P<0.001)$ & $-1.893 \pm 1.071(P=0.089)$ & $0.197 \pm 0.445(P=0.671)$ & $4.196 \pm 1.476(P<0.001)$ & $0.440 \pm 0.099$ & $0.187 \pm 0.072$ \\
\hline
\end{tabular}

Abbreviations: n.e., non-estimated; PHA, phytohemagglutinin.

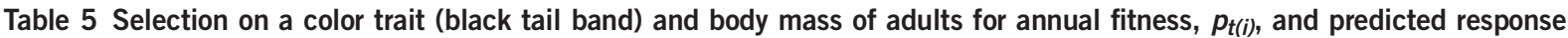

\begin{tabular}{|c|c|c|c|c|c|c|}
\hline Trait & $S_{i}^{\prime} \pm$ s.e. & $c_{i}^{\prime} \pm$ s.e. & $\beta_{i}^{\prime} \pm$ s.e. & $\gamma_{i}^{\prime} \pm$ s.e. & $\gamma_{\mathrm{ij}}^{\prime} \pm$ s.e. & $\begin{array}{l}\text { Predicted } \\
\text { response }(\mathrm{R})\end{array}$ \\
\hline $\begin{array}{l}\text { Females } \\
\text { Body mass } \\
\text { Black tail band }\end{array}$ & $\begin{array}{l}0.086 \pm 0.023(P<0.001) \\
0.028 \pm 0.024(P=0.234)\end{array}$ & $\begin{array}{l}-0.026 \pm 0.032(P=0.430) \\
-0.030 \pm 0.032(P=0.365)\end{array}$ & $\begin{array}{l}0.074 \pm 0.025(P=0.004) \\
0.026 \pm 0.025(P=0.309)\end{array}$ & $\begin{array}{l}-0.022 \pm 0.034(P=0.513) \\
-0.024 \pm 0.036(P=0.513)\end{array}$ & $-0.042 \pm 0.025(P=0.097)$ & $\begin{array}{l}0.044 \\
0.025\end{array}$ \\
\hline $\begin{array}{l}\text { Males } \\
\text { Body mass } \\
\text { Black tail band }\end{array}$ & $\begin{array}{l}0.006 \pm 0.024(P=0.795) \\
0.029 \pm 0.024(P=0.226)\end{array}$ & $\begin{array}{l}-0.018 \pm 0.032(P=0.592) \\
-0.076 \pm 0.032(P=0.020)\end{array}$ & $\begin{array}{r}-0.003 \pm 0.025(P=0.915) \\
0.028 \pm 0.025(P=0.249)\end{array}$ & $\begin{array}{r}0.002 \pm 0.032(P=0.936) \\
-0.078 \pm 0.034(P=0.020)\end{array}$ & $-0.057 \pm 0.024(P=0.017)$ & $\begin{array}{r}-0.006 \\
0.024\end{array}$ \\
\hline
\end{tabular}

Standardized directional and stabilizing selection differentials $\left(S^{\prime}\right.$ and $\left.C^{\prime}\right)$ were estimated from linear regressions and standardized directional and nonlinear selection gradients $\left(\beta^{\prime}\right.$ and $\left.\gamma^{\prime}\right)$ and correlated selection $\left(\gamma^{\prime}\right.$ ij) from multiple linear regressions. The predicted response to selection based on multivariate selection gradients $\left(\beta^{\prime}\right)$ is given for traits with significant heritable variance.
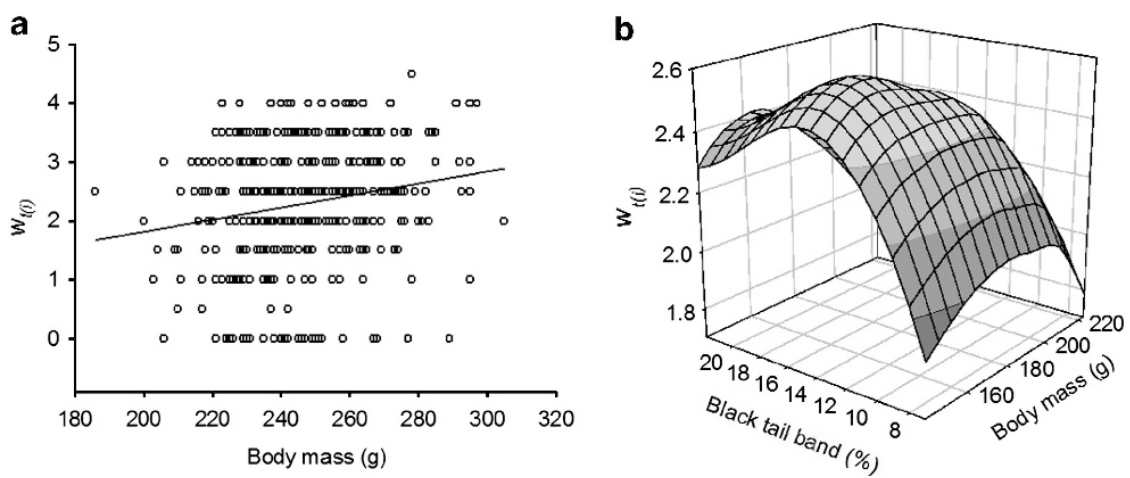

Figure 1 Selection on adult phenotypes. (a) Linear selection on female body mass $(N=414)$ and (b) correlational selection on male body mass and black tail band width $(N=229)$.

(eg Antoniazza et al., 2010; Karell et al., 2011). Black tail band width of adults and rump gray color of fledglings showed a significant heritability in both males and females ( $h^{2}$ ranging from 0.09 to 0.84 ). Previously, it has been thought that the expression of melanin-based plumages depend mainly on strong genetic control (Hill and McGraw, 2006b). However, our results showed that annual variations in environmental conditions partly influence their phenotypic variations in the common kestrel (see also Fargallo et al., 2007b; Vergara et al., 2009 for evidence in the study population and Fargallo et al., 2007a; Parejo and Silva, 2009 for other populations). The extent of gray coloration of rump showed weak genetic variation in female adults, suggesting that the phenotypic variation of this character depends mainly on environmental influences. The quantitative genetics analysis also provided evidence of strong additive genetic effects for body mass (adults and fledglings, $h^{2}$ ranging from 0.53 to 0.89 ) and PHA-mediated immune response (fledglings, $h^{2}=0.47-0.55$ ). Particularly, the heritability of response to PHA of avian young was surprisingly high compared with other bird populations estimated using either animal model approach or full-sibling analysis (Ardia and Rice, 2006; Pitala et al., 2007; but see Bonneaud et al., 2009).

These heritable traits, melanin-based color traits, body mass and immune response, were correlated at the genetic and/or phenotypic levels. Negative genetic covariance between melanin coloration and body mass in male adults and positive genetic covariance between body mass and PHA-mediated immune response in fledglings of both sexes are as predicted by the pleiotropic effect of high MCR activity. 


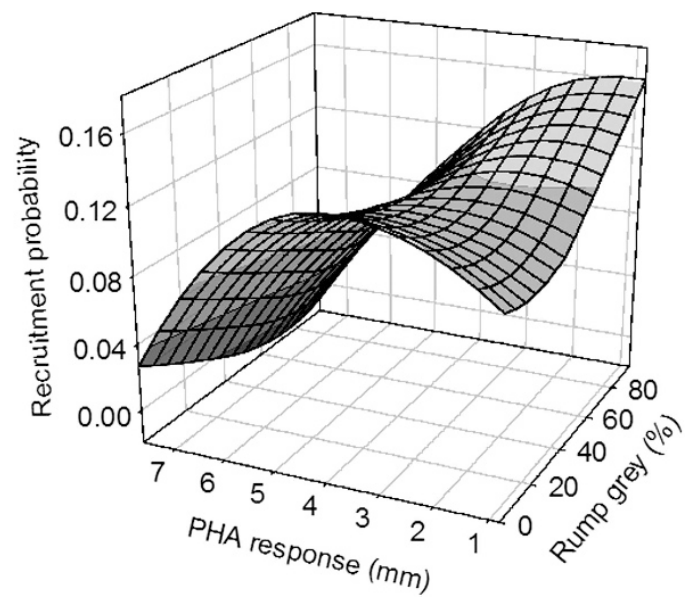

Figure 2 Correlational selection on PHA-mediated immune response and rump gray coloration in male fledglings $(N=416)$.

MCR activity increases melanogenesis but reduces adult body mass through low food intake or high energy expenditure (Ste. Marie et al., 2000; Makimura et al., 2002). In insects, strong evidence of pleiotropy between melanin pigmentation and innate immunity (through the genes encoding Tyrosine Hydroxylase and Dopa-decarboxylase) is well documented (reviewed in Wittkopp and Beldade, 2009). In mammals, MCR activity mediates the pleiotropic relationship between melanin coloration and immunity by reducing acute and allergic skin inflammation (Teofoli et al., 1999; Getting et al., 2001), and this may be the case also in birds. Alternatively, the negative covariances between melanin coloration, body mass and immune response may indicate the presence of resource allocation trade-offs, although it is unclear whether those functions compete for the same resources.

The negative genetic covariance between adult melanin coloration and body mass appeared only in males, possibly because the gene expression for melanocortins is stronger in males in which show stronger melanin coloration than females. In fledglings, we did not find evidence of genetic covariance between rump gray color and other two traits (body mass and PHA-mediated immune response), contrary to our prediction drawn from the pleiotropic effect of the $P O M C$ gene. A potential explanation can be that the relative contribution of $P O M C$ gene to these complex traits related to physiology and metabolism is relatively minor compared with its contribution to melanin coloration. Alternatively, the influence of other important candidate genes involved in physiological and metabolic functions, for example, the major histocompatibility complex $(M h c)$ genes, may be biased among those traits (Bonneaud et al., 2009). The melanocortin system is involved in many different physiological and behavioral functions (Ducrest et al., 2008). Our findings based on some of those functions probably demonstrate only limited aspects of their genetic and phenotypic interactions.

The genetic covariability among morphological and physiological traits found in this study suggests the complexity of predicting evolutionary responses of these traits. Most remarkably, the negative genetic correlation between black tail band and body mass in male adults may act as a constraint on evolutionary responses for both traits. On the other hand, the positive genetic correlation between body mass and PHA-mediated immune response predicts coevolution of these traits if there is directional selection acting on either trait.

Black tail band, which is negatively correlated to body mass at the additive genetic level, showed a significant stabilizing selection in male 
breeders. The stabilizing selection together with a significant correlational selection with body mass provides evidence that natural selection favors male breeders that simultaneously exhibit intermediate phenotypic values for the two traits, leading to little evolutionary change. However, natural selection favored heavier individuals in female breeders. The differences in multivariate inheritance and selection between male and female kestrels might have resulted in sexual dimorphism by allowing females to evolve larger in size but males stronger in melanin-based color traits (Hedrick and Temeles, 1989; Arnqvist and Rowe, 2005). Furthermore, the pleiotropic effects of melanocortins in male characters may also include increased aggressiveness and sexual activity that possibly enhance fitness but also fast metabolism that accelerates somatic senescence and short lifespan (Ducrest et al., 2008).

Interesting finding in selection of chick characters is that males (but not females) with an intermediate level of PHA-mediated immune response were selected, whereas rump gray color showed a disruptive selection. There was also a correlated selection on the two traits. In this population, grayer males received extended parental care after fledging over a longer period than browner male fledglings (Vergara et al., 2010). This biased parental provisioning after fledging might increase recruitment probability of grayer males, but it is unclear why brownest males were also selected. It is possible that the phenotypic expression of gray coloration trades off physiological conditions that influence post-fledging survival, as evidenced by the negative phenotypic correlation between PHA-mediated immune response and gray color at fledging. Furthermore, the social costs that impose gray coloration in young kestrels (Vergara et al., 2013) may also explain the higher recruitment of brownish individuals.

Our results of multivariate inheritance and selection provide an insight into the evolution of multivariate traits genetically related with melanin-based coloration, which is expressed in a great variety of taxa, including humans. Evolutionary studies often try to explain the evolution of animal coloration with its biological functions such as protection, concealment and advertisement (Hill and McGraw, 2006a). However, it is not easy to find evidence for direct directional selection acting on color traits (Roulin et al., 2010), except for those directly related to sexual selection, as also shown in the present study. When pleiotropic effects of color traits on other important vital functions are present, coloration can evolve through a complex pathway involving correlated response to selection on multivariate traits. Many questions about the evolution of melanin coloration still remain, including how sex-specific selection and inter-sexual genetic covariability influence the evolution of sexual dimorphism in color and other genetically related traits, and whether environmental conditions influence heritable variance and covariance of these traits (that is, genotype by environment interaction). Answers for these remained questions together with the present study will undoubtedly improve our understanding on the evolution of animal coloration.

\section{DATA ARCHIVING}

Data deposited in the Dryad repository: doi:10.5061/dryad.269gp.

\section{CONFLICT OF INTEREST}

The authors declare no conflict of interest.

\section{ACKNOWLEDGEMENTS}

We are most grateful to three anonymous referees for very helpful advice. A. Velando helped to conceive the study and provided valuable comments on the earlier draft. We thank people who helped in the field and Finat family for allowing us to work in their property. This is one contribution of the El
Ventorrillo field station. This study was funded by the Spanish Ministry of Science and Innovation (projects: CGL2007-61395/BOS and CGL201015726/BOS). S-YK is supported by a Parga Pondal fellowship from the Xunta de Galicia, PV by a Marie Curie Intra-European Fellowship (PIEF-GA-2009-252499) and JM-P by a JAE-doc fellowship from the CSIC.

Antoniazza S, Burri1 R, Fumagalli L, Goudet J, Roulin A (2010). Local adaptation maintains clinal variation in melanin-based coloration of European barn owls (Tyto alba). Evolution 64: 1944-1954.

Ardia DR, Rice EB (2006). Variation in heritability of immune function in the tree swallow. Evol Ecol 20: 491-500.

Ardia DR, Schat KA (2008). Ecoimmunology. In: Davison F, Kaspers B, Schat KA (eds) Avian Immunology. Elsevier: New York, pp 421-441.

Arnold SJ, Wade MJ (1984a). On the measurement of natural selection: theory. Evolution 38: 709-719.

Arnold SJ, Wade MJ (1984b). On the measurement of natural selection: practice. Evolution 38: 720-734.

Arnqvist G, Rowe L (2005). Sexual Conflict. Princeton University Press: Princeton.

Bonneaud C, Sinsheimer JS, Richard M, Chastel O, Sorci G (2009). Mhc polymorphisms fail to explain the heritability of phytohaemagglutinin-induced skin swelling in a wild passerine. Biol Lett 5: 784-787.

Brommer JE, Wilson AJ, Gustafsson L (2007). Exploring the genetics of aging in a wild passerine bird. Am Nat 170: 643-650.

Casagrande S, Csermely D, Pini E, Bertacche V, Tagliavini J (2006). Skin carotenoid concentration correlates with male hunting skill and territory quality in the kestrel (Falco tinnunculus). J Avian Biol 37: 190-196.

Charmantier A, Reale D (2005). How do misassigned paternities affect the estimation of heritability in the wild? Mol Ecol 14: 2839-2850.

Coltman DW (2005). Testing marker-based estimates of heritability in the wild. $\mathrm{Mol} \mathrm{EcOl}$ 14: 2593-2599.

Coltman DW, O'Donoghue P, Hogg JT, Festa-Bianchet M (2005). Selection and genetic (co)variance in bighorn sheep. Evolution 59: 1372-1382.

Coulson T, Benton TG, Lundberg P, Dall SRX, Kendall BE, Gaillard J-M (2006). Estimating individual contributions to population growth: evolutionary fitness in ecological time. Proc R Soc Lond Ser B-Biol Sci 273: 547-555.

Ducrest A-L, Keller L, Roulin A (2008). Pleiotropy in the melanocortin system, coloration and behavioural syndromes. Trends Ecol Evol 23: 502-510.

Fargallo JA, Laaksonen T, Korpimäki E, Wakamatsu K (2007a). A melanin-based trait reflects environmental growth conditions of nestling male Eurasian kestrels. Evol Ecol 21: 157-171.

Fargallo JA, Laaksonen T, Poyri V, Korpimäki E (2002). Inter-sexual differences in the immune response of Eurasian kestrel nestlings under food shortage. Ecol Lett $\mathbf{5}$ : 95-101.

Fargallo JA, Martínez-Padilla J, Toledano-Díaz A, Santiago-Moreno J, Dávila JA (2007b). Sex and testosterone effects on growth, immunity and melanin coloration of nestling Eurasian kestrels. J Anim Ecol 76: 201-209.

Foerster K, Coulson T, Sheldon BC, Pemberton JM, Clutton-Brock TH, Kruuk LEB (2007). Sexually antagonistic genetic variation for fitness in red deer. Nature 447: 1107-1110.

Fridolfsson A-K, Ellegren $\mathrm{H}$ (1999). A simple and universal method for molecular sexing of non-ratite birds. J Avian Biol 30: 116-121.

Getting SJ, Allcock GH, Flower R, Perretti M (2001). Natural and synthetic agonists of the melanocortin receptor type 3 possess anti-inflammatory properties. J Leukocyte Biol 69: 98-104

Gilmour AR, Gogel BJ, Cullis BR, Thompson R (2008). ASRem/ User Guide, Release 3.0. VSN International Ltd, Hemel Hempstead.

Hedrick AV, Temeles ET (1989). The evolution of sexual dimorphism in animals: hypotheses and tests. Trends Ecol Evol 4: 136-138.

Hill GE, McGraw KJ (2006a). Bird Coloration: Function and Evolution. Harvard University Press: Cambridge.

Hill GE, McGraw KJ (2006b). Bird Coloration: Mechanisms and Measurements. Harvard University Press: Cambridge.

Hoekstra HE (2006). Genetics, development and evolution of adaptive pigmentation in vertebrates. Heredity 97: 222-234.

Houle D (1992). Comparing evolvability and variability of quantitative traits. Genetics 130: 195-204.

Hubbard JK, Albert J, Uy C, Hauber MC, Hoekstra HE, Safran RJ (2010). Vertebrate pigmentation: from underlying genes to adaptive function. Trends Genet 26: 231-239.

Husby A, Nussey DH, Visser ME, Wilson AJ, Sheldon BC, Kruuk LEB (2010). Contrasting patterns of phenotypic plasticity in reproductive traits in two great tit (Parus major) populations. Evolution 64: 2221-2237.

Husby A, Visser ME, Kruuk LEB (2011). Speeding up microevolution: the effects of increasing temperature on selection and genetic variance in a wild bird population. PLOS Biol 9: e1000585.

Karell P, Ahola K, Karstinen T, Valkama J, Brommer JE (2011). Climate change drives microevolution in a wild bird. Nat Comm 2: 208.

Korpimäki E, Lahti K, May CA, Parkin DT, Powell GB, Tolonen P et al. (1996). Copulatory behaviour and paternity determined by DNA fingerprinting in kestrels: effects of cyclic food abundance. Anim Behav 51: 945-955. 
Kruuk LEB (2004). Estimating genetic parameters in natural populations using the 'animal model'. Philos Trans R Soc Ser B-Biol Sci 359: 873-890.

Kruuk LEB, Slate J, Wilson AJ (2008). New answers for old questions: the evolutionary quantitative genetics of wild animal populations. Annu Rev Ecol Evol Syst 39: 525-548.

Lande R, Arnold SJ (1983). The measurement of selection on correlated characters. Evolution 37: 1210-1226.

Makimura H, Mizuno TM, Mastaitis JW, Agami R, Mobbs CV (2002). Reducing hypothalamic AGRP by RNA interference increases metabolic rate and decreases body weight without influencing food intake. BMC Neurosci 3: 18.

Martin LB, Han P, Lewittes J, Kuhlman JR, Klasing KC, Wikelski M (2006). Phytohemagglutinin-induced skin swelling in birds: histological support for a classic immunoecological technique. Funct Ecol 20: 290-299.

Martínez-Padilla J (2006). Daytime variation in T-cell-mediated immunity of Eurasian kestrel Falco tinnunculus nestlings. J Avian Biol 37: 419-424.

McGuigan K, Rowe L, Blows MW (2011). Pleiotropy, apparent stabilizing selection and uncovering fitness optima. Trends Ecol Evol 26: 22-29.

Merilä J, Sheldon BC, Ellegren H (1998). Quantitative genetics of sexual size dimorphism in the collared flycatcher, Ficedula albicollis. Evolution 52 870-876.

Morrissey MB, Wilson AJ (2010). Pedantics: an R package for pedigree-based genetic simulation and pedigree manipulation, characterization and viewing. Mol Ecol Resour 10: 711-719.

Mundy NI (2006). Genetic basis of color variation in wild birds. In: Hill GE, McGraw KJ (eds) Bird Coloration: Mechanisms and Measurements. Harvard University Press: Cambridge, pp 469-506.

Parejo D, Silva N (2009). Methionine supplementation influences melanin-based plumage coloration in Eurasian kestrel, Falco tinnunculus, nestlings. J Exp Biol 212 3576-3582.

Parejo D, Silva N, Danchin E, Avilés JM (2011). Informative content of melanin-based plumage color in adult Eurasian kestrels. J Avian Biol 42: 1-12.
Pitala N, Gustafsson L, Sendecka J, Brommer JE (2007). Nestling immune response to phytohaemagglutinin is not heritable in collared flycatchers. Biol Lett 3: 418-421.

Roff DA (1997). Evolutionary Quantitative Genetics. Chapman and Hall: New York.

Roulin A, Altwegg R, Jensen H, Steinsland I, Schaub M (2010). Sex-dependent selection on an autosomal melanic female ornament promotes de evolution of sex ratio bias. Ecol Lett 13: 616-626.

Ste. Marie L, Miura GI, Marsh DJ, Yagaloff K, Palmiter RD (2000). A metabolic defect promotes obesity in mice lacking melanocortin-4 receptors. Proc Natl Acad Sci USA 97: 12339-12344.

Stinchcombe JR, Agrawal AF, Hohenlohe PA, Arnold SJ, Blows MW (2008). Estimating nonlinear selection gradients using quadratic regression coefficients: double or nothing? Evolution 62: 2435-2440.

Tella JL, Lemus JA, Carrete M, Blanco G (2008). The PHA test reflects acquired T-cell mediated immunocompetence in birds. PLOS ONE 3: e3295.

Teofoli P, Frezzolini A, Puddu P, De Pità O, Mauviel A, Lotti T (1999). The role of proopiomelanocortin-derived peptides in skin fibroblast and mast cell functions. Ann NY Acad Sci 885: 268-276.

Vergara P, Fargallo JA (2008). Sex, melanic coloration and sibling competition during the post-fledging dependence period. Behav Ecol 19: 847-853.

Vergara P, Fargallo JA, Martínez-Padilla J (2010). Reaching independence: food supply, parent quality, and offspring phenotypic characters in kestrels. Behav Ecol 21: 507-512.

Vergara P, Fargallo JA, Martínez-Padilla J, Lemus JA (2009). Inter-annual variation and information content of melanin-based coloration in female Eurasian kestrels. Biol J Linn Soc 97: 781-790.

Vergara P, Martínez-Padilla J, Fargallo JA (2013). Differential maturation of sexual traits: revealing sex while reducing male and female aggressiveness. Behav Ecol 24: 237-244.

Village A (1990). The Kestrel. T and AD Poyser: London.

Wittkopp PJ, Beldade P (2009). Development and evolution of insect pigmentation: genetic mechanisms and the potential consequences of pleiotropy. Semin Cell Dev Bio 20: 65-71.

Supplementary Information accompanies this paper on Heredity website (http://www.nature.com/hdy) 